\title{
Analisa Kualitas Hidup Pembalap Motor Road Race Pasca Mengalami Cedera Tulang Di Jawa Barat Menggunakan European Quality Of Life 5 Dimensions (EQ5D) EQ-5D-5L
}

\author{
Dedy Frianto*, Riska Novrianty \\ *dedyfrianto@ubpkarawang.ac.id \\ fm15.riskanovriyanti@mhs.ubpkarawang.ac.id \\ Fakultas Farmasi, Universitas Buana Perjuangan Karawang
}

\begin{abstract}
ABSTRAK
Olahraga balap motor khususnya Road Race cukup populer di Indonesia. Olah raga ini merupakan aktivitas yang dapat memberikan manfaat bagi kesehatan fisik maupun mental. Namun, jika tidak diimbangi kesadaran untuk menjaga keselamatan, sehingga mereka sangat rentan mengalami cedera yang dapat mengganggu kesehatan juga dapat mengurangi atlet tersebut untuk berprestasi secara maksimal. Penelitian ini bertujuan mengidentifikasi dan menganalisa bagaimana kualitas hidup para pembalap motor Road Race pasca mengalami cedera tulang dan terapi atau obat apa digunakan oleh para pembalap pasca mengalami cedera tulang tersebut.

Sampel penelitian ini adalah para pembalap yang diketahui telah mengalami cedera atau patah tulang di Jawa Barat. Desain penelitian menggunakan jenis Observasional Cross Sectional di mana pengumpulan data dilakukan dengan pengisian kuesioner secara prospektif pada semua pembalap di Jawa barat. Pengumpulan data dilakukan dengan menyebarkan kuesioner European Quality Of Life 5 Dimension (EQ5D5L) secara langsung kepada para pembalap pada Event Bupati Cup Seri 1 - Open Road Race 2.

Berdasarkan analisa data yang dilakukan, diperoleh kesimpulan bahwa kualitas hidup para pembalap pasca mengalami cedera tulang memiliki kualitas hidup yang baik karena didapatkan hasil rata-rata dari skala kesehatan terakhirnya yaitu 0,4888, di mana apabila responden memiliki skala kesehatan 1,000 atau lebih dari -0,594, maka responden dinyatakan memiliki kualitas hidup yang baik pasca mengalami cedera tulang.
\end{abstract}

Kata Kunci: Road Race, Pembalap, Cedera tulang, Kualitas hidup, EQ5D5L

\begin{abstract}
Motor racing, especially road racing, is one of the most popular sports in Indonesia. This sport is a benefical activity for physical and mental health. But unfortunately it is not balanced with the user's awareness to keep a self-safety so that racers are very risk to fracture injuries that can not only interfere with health but can also reduce the athletes themselves to achieve maximum performance. This study aims to identify and analyze how the quality of life of road racers after suffering fracture and what kind of therapy or medication to be used.

The sample of this study were the road racers known to have suffered injuries or fracture in West Java. The research design used the type of Cross Sectional Observational in which the data was collected by filling prospective questionnaires on all racers. Data collection was carried out by distributing the European Quality of Life 5 Dimension (EQ5D5L) questionnaire directly to the racers at the Series 1 Regent Cup Event - Open Road Race 2.

Based on the analysis of the data, it was concluded that the quality of life of the racers after suffering a bone injury had a good quality of life due to the fact that it obtained an average result from the final health scale of 0.4888 , if the respondent had a health scale of 1,000 or more of -0,594, it's stated that the respondents have a good quality of life after suffering a bone injury.
\end{abstract}

Keywords: Road race, Racers, Quality of life, EQ5D5L. 


\section{PENDAHULUAN}

Balap motor, khususnya Road race cukup populer di Indonesia. Selain itu, olahraga ini cukup banyak peminatnya, sayangnya hal itu tidak diimbangi kesadaran pengguna untuk menjaga keselamatan. Olahraga balap motor Road race ini merupakan aktivitas yang dapat memberikan manfaat bagi kesehatan fisik maupun mental, akan tetapi olahraga balap motor Road race dapat pula mendapatkan dampak merugikan bagi tubuh antara lain itu cedera tulang. Cedera yang terjadi pada atlet balap motor Road race selain mengganggu kesehatan juga dapat mengurangi atlet tersebut untuk berprestasi secara maksimal, cedera yang dialami para atlet yaitu cedera olahraga,cedera pada sistem integumen, otot dan rangka yang disebabkan oleh kegiatan olahraga.

Laporan tahunan Ikatan Motor Indonesia (IMI) tahun 2018 selaku panitia Road race, jumlah kejadian menurut mekanisme cedera, kecelakaan kendaraan bermotor menduduki peringkat utama atas jumlah terbanyak kemudian disusul dengan cedera akibat terjatuh. Perbandingan hasil IMI 2010 dengan IMI 2018 menunjukkan kecenderungan peningkatan prevalensi cedera dari 7,5\% menjadi 8,2\%. Penyebab cedera terbanyak, yaitu jatuh 58,4\% dan kecelakaan 41,6\%.

Fraktur merupakan suatu keadaan dimana terjadi disintegritas tulang, penyebab terbanyak adalah kecelakaan tetapi faktor lain seperti degenerative juga dapat berpengaruh terhadap kejadian fraktur (Brunner and Suddarth, 2008). Adapun kejadian kecelakaan yang sering terjadi pada road race menyebabkan beberapa orang/pembalap mengalami cedera tulang bahkan sampai kehilangan nyawa.

Pemilihan analisa kualitas hidup ini berdasarkan beberapa aspek, salah satunya karena seringkali terjadi kecelakaan yang dialami oleh pembalap motor, maka dari itu berdasarkan uraian di atas penelitian ini di latar belakangi untuk mengidentifikasi dan menganalisa Kualitas Hidup Pembalap Motor Road Race Pasca Mengalami Cedera Tulang di Jawa Barat Menggunakan kuisioner European Quality Of Life 5 Dimensions EQ-5D-5L.

Euro Quality of Life (EQ-5D) merupakan instrumen general yang telah digunakan secara luas untuk mengukur status kesehatan suatu populasi (Rabin dan Charro, 2001). EQ-5D terdiri dari dua bagian yaitu EQ-5D descriptive system dan EQ5D Visual Analogue Scale (VAS). EQ-5D descriptive system mengukur status kesehatan seseorang menggunakan 5 domain yang terdiri dari mobility, self-care, usual activity, 
pain/discomfort, dan anxiety/depression. EQ-5D VAS mencatat penilaian responden terhadap kesehatannya menggunakan Visual Analogue Scale berbentuk vertikal yang memiliki skala 0-100. Skala 0 menunjukkan status kesehatan terburuk sedangkan skala 100 menunjukkan status kesehatan terbaik. Terdapat dua versi instrumen EQ-5D yang tersedia saat ini, yaitu EQ-5D-3L yang memiliki 3 kategori tingkatan respon dan EQ-5D5L yang merupakan instrumen EQ-5D versi terbaru memiliki 5 kategori tingkatan respon (Reenen and Janssen, 2015). Instrumen EQ-5D dapat digunakan untuk mengukur kualitas hidup baik pada populasi umum maupun pada populasi dengan kondisi khusus seperti pada populasi pembalap motor yang mengalami cedera tulang.

Penelitian mengenai Analisa Kualitas Hidup Pembalap Motor Road Race Pasca Mengalami Cedera Tulang Di Jawa Barat Menggunakan European Quality Of Life 5 Dimensions EQ-5D-5L belum pernah dilakukan terhadap populasi pasien fraktura, khususnya di Jawa barat. Adanya variasi sosio-demografi dan budaya pada masingmasing negara dapat berpengaruh terhadap hasil pengukuran kualitas hidup.

Dalam penelitian yang dilakukan oleh (War and Rajeswaren, 2013) didapatkan data bahwa pada pasien pasca cedera akan mengalami penurunan kualitas hidup, yang meliputi gangguan kesehatan fisik sebanyak 58,23\%, mengalami gangguan kesehatan psikologis sebanyak 53,17\%, terjadi gangguan hubungan sosial sebanyak 56,23\%, dan sebanyak 55,03\% mengalami gangguan lingkungan. Adapun jenis pengobatan yang banyak digunakan oleh orang-orang awam pada umumnya ketika patah tulang adalah pergi ke ahli tulang dan hanya mengkonsumi obat anti nyeri saja. Mereka kebanyakan ketika mengalami cedera tulang akan langsung dibawa ke ahli tulang dibandingkan pergi ke dokter.

\section{METODE PENELITIAN}

\section{Rancangan Penelitian}

Desain penelitian menggunakan jenis Observasional Cross Sectional dengan pengumpulan data dilakukan dengan pengisian kuesioner secara prospektif pada semua pembalap di Jawa barat. Data dikumpulkan menggunakan instrumen Kuesioner European Quality Of Life 5 Dimension EQ-5D-5L. 


\section{Tempat dan Waktu Penelitian}

Penelitian dilaksanakan di sirkuit Daerah Majalengka pada tanggal 27-28 Juli 2019 di event Bupati Cup Seri-1 Open Road Race. Penelitian ini dilakukan kepada pembalap-pembalap yang pernah mengalami cedera tulang (fraktur) yang ada di Jawa barat.

\section{Populasi}

Populasi dalam penelitian ini adalah semua pembalap yang diketahui telah mengalami fraktur (patah tulang) di sirkuit Jawa Barat yang mengikuti Road Race majalengka.

\section{Subjek Penelitian}

\section{Kriteria inklusi}

Pembalap motor yang mengalami cedera tulang sebelum penelitian.

Pembalap yang bersedia menjadi responden.

\section{Kriteria Ekslusi}

Pembalap tidak bersedia menjadi responden.

\section{Analisa Data}

Data yang diambil yaitu dengan mengambil semua populasi pembalap pada Event Bupati Cup Seri 1 - Open Road Race 2, data dikumpulkan menggunakan instrumen Kuesioner European Quality Of Life 5 Dimension EQ-5D-5L mencakup lima dimensi kesehatan. Analisi data

\section{HASIL DAN PEMBAHASAN}

\section{Klasifikasi Responden Berdasarkan Cedera}

Tabel 1. Klasifikasi Responden Berdasarkan Cedera

\begin{tabular}{lcc}
\hline \multicolumn{1}{c}{ Jenis cedera } & Frekuensi & \% \\
\hline Retak Kaki & 5 & $21 \%$ \\
\hline Patah Kaki & 4 & $17 \%$ \\
\hline Retak Tulang Punggung & 2 & $8 \%$ \\
\hline Retak Tulang Ekor & 1 & $4 \%$ \\
\hline Retak Pergelangan Tangan & 1 & $4 \%$ \\
\hline Patah Bahu & 3 & $13 \%$ \\
\hline Dislokasi Bahu & 5 & $21 \%$ \\
\hline Patah Lengan & 1 & $4 \%$
\end{tabular}




\begin{tabular}{lll}
\hline Dislokasi Tangan & 1 & $4 \%$ \\
\hline Dislokasi Lutut & 1 & $4 \%$ \\
\hline
\end{tabular}

Berdasarkan tabel diatas menunjukan bahwa yang mengalami cedera retak kaki ada 5 orang (21\%), yang mengalami patah kaki sebanyak 4 orang (17\%), yang mengalami retak tulang punggung ada 2 orang (8\%), yang mengalami retak tulang ekor ada 1 orang (4\%), yang mengalami retak pergelangan tangan ada 1 orang (4\%), yang mengalami patah bahu ada 3 orang (13\%), yang mengalamiu dislokasi bahu ada 5 orang (21\%), yang mengalami patah lengan ada 1 orang (4\%), yang mengalami dislokasi tangan sebanyak 1 orang (4\%), dan yang mengalami dislokasi lutut ada 1 orang (4\%). Adapun pengujian statistik berdasarkan jenis cedera untuk melihat pengaruh jenis cedera terhadap kualitas hidup pembalap adalah dinyatakan berpengaruh apabila nilai sig $<0,05$ untuk mengetahuinya ditabel sebagai berikut:

\begin{tabular}{cccccccc}
\hline & & \multicolumn{6}{c}{ Levene's Test for Equality of Variances } \\
\cline { 3 - 7 } & & $\mathrm{F}$ & Sig. & $\mathrm{T}$ & $\mathrm{df}$ & $\begin{array}{c}\text { Sig. (2- } \\
\text { tailed) }\end{array}$ \\
\hline \multirow{2}{*}{$\begin{array}{c}\text { Hasil jenis } \\
\text { cedera }\end{array}$} & $\begin{array}{c}\text { Equal } \\
\text { variances } \\
\text { assumed }\end{array}$ & 42,186 & 0 & 6,258 & 32 & 0 \\
\cline { 2 - 7 } & $\begin{array}{c}\text { Equal } \\
\text { variances not } \\
\text { assumed }\end{array}$ & & & 4,269 & 9,615 & 0,002 \\
\hline
\end{tabular}

Gambar 1. Hasil SPSS UJI T berdasarkan Jenis Cedera

Berdasarkan hasil uji sampel $t$ berdasarkan jenis cedera yang disajikan pada gambar diatas dapat dilihat nilai dari sig dari jenis Cedera adalah nilai sig (2-tailed) didapatkan hasil 0.000 yang artinya $<0.05$ itu berarti uji sampel $t$ jenis cedera adanya pengaruh terhadap kualitas hidup pasca mengalami cedera tulang (fraktur).

Jenis cedera berpengaruh terhadap kualitas hidup karena apabila seseorang sedang menderita cedera fraktur, sudah pasti aktivitasnya akan terganggu, bisa dilihat dari penurunan pada kemampuan berjalannya, serta akan kesulitan pada perawatan diri sendiri, serta akan menganggu kegiatan yang biasa dilakukan, dan selalu merasakan rasa nyeri, karena mereka merasa cemas/takut tidak bisa kembali normal seperti semula. 


\section{Klasifikasi responden berdasarkan obat}

Tabel 2. klasifikasi responden berdasarkan obat

\begin{tabular}{lcc}
\hline Obat yang digunakan & Frekuensi & $\boldsymbol{\%}$ \\
\hline Diclofenac Sodium & 10 & $42 \%$ \\
\hline Tramadol & 12 & $50 \%$ \\
\hline Meloxicam & 2 & $8 \%$ \\
\hline
\end{tabular}

Berdasarkan tabel diatas yang mengkonsumsi obat diclofencac sodium ada 10 orang (42\%) dan yang mengkonsumsi tramadol ada 12 orang (50\%) dan yang mengkonsumsi meloxicam 2 orang (8\%).

\section{KESIMPULAN}

Berdasarkan hasil penelitian dan pembahasan dapat disimpulkan bahwa kualitas hidup pembalap pasca mengalami cedera tulang memiliki kualitas hidup yang baik karena didapatkan hasil rata-rata dari skala kesehatan terakhirnya yaitu 0,4888, Dimana apabila responden memiliki skala kesehatan 1,000 atau lebih dari -0,594, responden dinyatakan memiliki kualitas hidup yang baik pasca mengalami cedera tulang. Dalam penelitian ini didapatkan data pembalap yang mengalami cedera tulang yang mengalami gangguan kemampuan berjalan sebanyak 54\%, mengalami gangguan pada perawatan diri $13 \%$, mengalami gangguan pada kegiatan yang biasa dilakukan 17\%, mengalami gangguan rasa nyeri/tidak nyaman sebanyak $8 \%$, mengalami rasa cemas/depresi sebanyak $8 \%$.

Jenis terapi yang banyak dipilih pembalap pasca mengalami cedera tulang adalah kepada ahli tulang sebanyak 54\%. Karena mereka setelah mengalami kecelakaan atau terjatuh langsung dibawa kepada ahli tulang, karena ke ahli tulang biaya lebih murah dan pengobatannya manual, sedangkan apabila ke dokter merasa takut karena selain biaya nya lebih mahal pegobatannya pun dokter biasanya langsung memvonis/menyarankan operasi untuk yang patah tulang atau pergeseran bahu. Dan obat yang paling banyak digunakan pada responden adalah obat tramadol sebanyak 50\%, sementara yang menggunakan obat diclofenac sodium ada $42 \%$ dan yang menggunakan obat meloxicam ada $8 \%$. 


\section{DAFTAR PUSTAKA}

Andun Sudijandoko. (2010). Pembelajaran Pendidikan Jasmani Yang Efektif dan Berkualitas. Jurnal Pendidikan Jasmani Indonesia

Angriyani, D. (2008). Kualitas Hidup pada Orang dengan Penyakit Lupus Erythematotus (Odapus). Skripsi Fakultas Psikologi Universitas Airlangga. Tidak Dipublikasikan.

Annisa, F.N., 2013, Faktor Yang Berhubungan Dengan Kepatuhan Berobat Hipertensi Pada Lansia Di Puskesmas Pattingalloang Kota Makassar, Naskah Publikasi, Fakultas Kesehatan Masyarakat Universitas Hassanudin, Makassa

Apley A.G and Solomon L. 1995. Buku Ajar Orthopedi dan Fraktur Sistem Apleyedisi 7. Diterjemahkan oleh dr. Edy Nugroho. Jakarta: Widya.

Apley. A. G. and Solomon.L. 2010. Apley's system of ortopedic and fracture unitedkingdom. hodder amold.

Brunner \& Suddarth. (2008). Buku Ajar Keperawatan Medikal Bedah edisi 8 vol 1, alih bahasa, Agung Waluyo et al; editor edisi bahasa Indonesia, Monica Ester. Jakarta: EGC.

Byers,S.N. 2008.Basics of Human Osteology and Odontology.Introduction to Forensic Anthropology. Third Edition. Boston.28-59

Corwin, 2001; Rehabilitasi Paru; Dalam Gorrison, S(ed); Dasar -Dasar Terapi danRehabilitasi Fisik; Cetakan ke 1, Hipokrates, Hal. 280 -282.

Dahlan,Sopiyudin ,2014. Statistik Untuk Kedokteran Dan Kesehatan Edisi 6. Jakarta, Salmba Medika.

Doenges, M E dkk (2002). Rencana Asuhan Keperawatan: pedoman untuk perencanaan dan pendokumentasian perawatan pasien . Jakarta: EGC.

Engram, B., 1998, Rencana Asuhan Keperawatan Medical Bedah, Volume II, EGC, Jakarta.

Hardianto Wibowo. (1995). Pencegahan dan Penatalaksanaan Cedera Olahraga. Jakarta : Penerbit Buku Kedokteran

Hardianto, D., 2005. Media Pendidikan Sebagai Sarana Pembelajaran yang Efektif. Majalah Ilmiah Pembelajaran. 1 (1): 950-104

https://www.alodokter.com/apa-yang-dimaksud-dengan-fisioterapi

Moore KL., Agur AMR. 2002. Anatomi Klinis Dasar. Hipokrates. Jakarta. 
Nimas,F.(2012).KualitasHidupPadaPenderitaKankerServiksyangMenjalani

PengobatanRadioterapi. Jurnal Psikologi Klinis dan Kesehatan Mental,1(02), Juni 2012.

Potter \& Perry. (2005). Buku Ajar Fundamental Keperawatan Konsep, Proses, dan Praktik. Edisi 4 volume 1.EGC. Jakarta

Rabin, R. dan Charro, F., 2001, EQ-SD: a Measure of Health Status from the EuroQol Group, Ann Med, 33, 337-43.

Rapley, Mark. (2003). Quality of Life Research A Critical Introduction. London: SAGE Publications, Inc.

Reenen, M. dan Janssen, B., 2015, EQ-5D-5L User guide: Basic Information on How to Use the EQ-5D-5L Instrument, EuroQol Group.

Reeves, C ,dkk., 2001. Keperawatan Medikal Bedah. Penerbit Salemba Medika. Jakarta Rubbyana, Urifah (2012). Hubungan antara Strategi Koping dengan Kualitas Hidup pada Penderita Skizofrenia Remisi Simptom. Jurnal Psikologi Klinis dan Kesehatan MentalUniversitas Airlangga Surabaya . Volume 1, Nomor 02, Juni 2012.

Sharkey, Brian J,2003. Kebugaran \& Kesehatan. PT Rajagrafindo Persada : Jakarta.

Smeltzer, S. C., Bare, B. G., 2001, "Buku Ajar Keperawatan Medikal-Bedah Brunner \&Suddarth. Vol. 2. E/8”, EGC, Jakarta.

Snell, R.S. 2012. Anatomi Klinik Berdasarkan Sistem. Dialihbahasakan oleh Suguharto L. Jakarta:EGC

Stevens et al. (2000). Ilmu keperawatan, Edisi 2., Jakarta: EGC.

Sudijandoko, Andun. 2000. Perawatan Dan Pencegahan Cedera, Jakarta: Departemen Pendidikan Nasional.

Syaifuddin. 2009. Anatomi Tubuh Manusia Edisi 2. Jakarta: Salemba Medika.

Tortora GJ, Derrickson B. 2011. Principles of Anatomy and Physiology Maintanance and Continuity of the Human Body 13th Edition. Amerika Serikat: John Wiley \& Sons, Inc.

War, F \& Rajeswaren, J, (2013). Quality of life and perception of illness in patients with traumatic brain injury : The Indian Journal Of Neurotrauma 10 (115-119), Elsevier

Ware, J.E., Sherbourne, C. D.. 1992 The MOS 36 Item Short Form Healty Survey(SF36).I Conseptual Framework Item Selection.Med Care,30(6): 473-483. 
Widjanarko. B. 2010. 3. Plasenta. http://obginumj. Blogspot.com/2010 0801 archive. Html. Diunduh 21 November 2013.

World Health Organization (WHO) 2014. Commission on Ending Childhood Obesity. Geneva, World Health Organization, Departement of Noncommunicable disease surveillance.

World Health Organization. The world health report 1996: fighting diease-fostering development, Geneva: WHO; 1996. P. 137 